\title{
Effect of urban versus rural residence and of maternal education on infant health in South Lebanon
}

\author{
H ZURAYK, M TAWIL, AND E GANGAROSA \\ From the Faculty of Health Sciences, American University of Beirut, Beirut, Lebanon
}

SUMMARY A sample of 253 women from rural and urban areas of south Lebanon were visited for 18 months after delivery. Information was collected on patterns of reproduction, infant feeding, and use of the health services. The findings indicate that educated women and women living in urban areas were better off in terms of family formation patterns, immunisation, and well-baby care. The importance of educating women, particularly in rural areas, as a policy that can be varied to improve child health and growth is thus emphasised. The study also indicates, however, the special need for health education programmes directed to all mothers to emphasise proper breast-feeding patterns and the importance of preventive health care for infants. The findings also indicate the need for a more diversified system of delivering health care in which properly trained paramedical personnel take part, particularly in rural areas.

Child health is a major concern in developing countries because of the size of the child population and the sensitivity of infants to the ecological conditions existing in such countries. ${ }^{1}$ Among the conditions that intensify problems in child health in developing countries are the low level of education of the mother on whom the young child is totally dependent for care and the nature and scarcity of health services, particularly in rural areas. ${ }^{1-3}$

In this paper we are concerned with assessing the influence of maternal education and of place of residence (urban $v$ rural) on patterns of reproduction, infant feeding, and use of the health services. Urban residence is considered to be associated with improved availability and quality of health services. We are concerned with the education of the mother and the characteristics of the health services delivery system because they are important policy variables in the hands of development planners, and can be used to influence the level and patterns of child health and survival in developing countries.

\section{Sample and data collection}

An 18-month prospective survey started in July 1977 of 253 newly delivered married women living in south Lebanon. In June 1977 households in the villages of the Nabatieh and Zahrani districts of south Lebanon, as well as households in one section of the city of Sidon, were visited, and women who had delivered a live infant in the months of March to June 1977 were asked to join the study. Subsequently, each woman was visited 12 times, roughly once every six weeks. ${ }^{*}$ At each visit the woman was questioned about breast-feeding and use of contraceptives. She was also asked whether she had had her child immunised and if so the type and date of immunisation, whether she had taken her infant for a medical inspection, and, if so, the details.

A specially trained interviewer living in south Lebanon collected the information, under supervision of a research assistant from the university. Despite political problems in the area during the study period, the response of the women was very good. At the end of the study, only 22 women (8\%) had been lost to the study: 12 husbands left the village to seek work outside, six families moved out, three infants died, and one woman refused to continue after two visits.

We compared rural women with urban women living in the city of Sidon. Sidon is the third largest city in Lebanon and the largest city in the south. Women were also compared by level of education. Illiterate women and women who had not completed primary education (six years of schooling) were

\footnotetext{
There were some minor interruptions in schedules of visits throughout the 18 months whenever fighting broke out in the area. The third visit took more than six weeks to complete because the field worker got married at the time of the visit and took a short holiday.
} 
classified into a low education group and women who had completed primary education or above into a high education group.

\section{Results}

The characteristics of the study sample are summarised in table 1 .

\section{PATTERNS OF REPRODUCTION}

Family formation patterns are known to affect the state of health of family members, particularly of

Table 1 Characteristics of the study sample

\begin{tabular}{|c|c|c|}
\hline Characteristic & Rural & Urban \\
\hline No of women & 156 & 97 \\
\hline Mean age at interview (years) & $28 \cdot 1$ & $25 \cdot 4$ \\
\hline Mean age at marriage (years) & $18 \cdot 3$ & $19 \cdot 2$ \\
\hline Mean No of live births & 5.4 & $2 \cdot 9$ \\
\hline Mean No of living children & $5 \cdot 0$ & $2 \cdot 8$ \\
\hline Mean No of desired children & $4 \cdot 5$ & 3.6 \\
\hline \multirow{2}{*}{ Mean No of live births to women aged 35 or older } & $9 \cdot 1$ & $4 \cdot 4$ \\
\hline & $\%$ & $\%$ \\
\hline Illiterate & $48 \cdot 1$ & $7 \cdot 2$ \\
\hline Occupation housewife & $94 \cdot 3$ & $84 \cdot 6$ \\
\hline Husband illiterate & $22 \cdot 4$ & $14 \cdot 4$ \\
\hline \multicolumn{3}{|l|}{ Occupation of husband: } \\
\hline Farming & $19 \cdot 2$ & $1 \cdot 0$ \\
\hline Unskilled labour & $14 \cdot 7$ & $14 \cdot 4$ \\
\hline Skilled labour & $27 \cdot 6$ & 33.0 \\
\hline Business & 18.6 & $28 \cdot 8$ \\
\hline Armed Forces, police & $7 \cdot 7$ & $6 \cdot 2$ \\
\hline Teacher, clerk & $9 \cdot 0$ & 10.4 \\
\hline Other & $3 \cdot 2$ & $6 \cdot 2$ \\
\hline Living in extended families & $21 \cdot 2$ & $20 \cdot 6$ \\
\hline Married to relatives & 33.9 & 20.6 \\
\hline
\end{tabular}

young children. ${ }^{4}$ Table 2 presents the average birth order of the newborn infant by education of mother and urbanisation of the place of residence. It indicates a rapid pattern of reproduction for women in all four groups. Infants born to women of low education who reside in rural areas, however, are shown to have higher birth orders, on average, than infants born to educated women and to women residing in urban areas.

In addition, rural women with low education have the shortest mean preceding birth interval (27 months) among women with at least one previous birth. Differences with other groups are not significant. Forty per cent of the women in the study sample became pregnant within 18 months of delivery. Further follow-up showed that only 12 of these women experienced an abortion.

\section{BREAST-FEEDING PATTERNS}

For all groups, the average duration of complete breast-feeding is below the recommended period of four to six months (table 3 ). ${ }^{56}$ Interesting differentials are observed, however, in terms of the total duration of breast-feeding (wholly and partial) by education and place of residence. Whereas a significant association exists between poor education and prolonged total breast-feeding for rural women, no significant effect by education is shown by the urban women. Moreover, while a significant difference exists among women of low education by place of residence, no such difference is observed for

Table 2 Mean age of mother and mean birth order of study infant by place of residence and education

\begin{tabular}{|c|c|c|c|c|c|c|}
\hline \multirow[b]{3}{*}{ Place of residence } & \multicolumn{6}{|l|}{ Education } \\
\hline & \multicolumn{3}{|l|}{ Low* } & \multicolumn{3}{|l|}{ Hight } \\
\hline & No of women & $\begin{array}{l}\text { Mean age } \\
\text { at delivery }\end{array}$ & Mean birth order & No of women & $\begin{array}{l}\text { Mean age } \\
\text { at delivery }\end{array}$ & Mean birth order \\
\hline $\begin{array}{l}\text { Rural } \\
\text { Urban } \\
\text { Total }\end{array}$ & $\begin{array}{r}97 \\
21 \\
118\end{array}$ & $\begin{array}{l}30.4 \\
27.2 \\
29.8\end{array}$ & $\begin{array}{l}6.3 \\
3.6 \\
5.9\end{array}$ & $\begin{array}{r}59 \\
76 \\
135\end{array}$ & $\begin{array}{l}24 \cdot 4 \\
24 \cdot 9 \\
24 \cdot 7\end{array}$ & $\begin{array}{l}3 \cdot 1 \\
2 \cdot 6 \\
2 \cdot 8\end{array}$ \\
\hline
\end{tabular}

"Illiterate or with under six years of schooling.

tSix years of schooling (primary education certificate) or above.

Table 3 Mean duration in months of wholly breast feeding and total (wholly and partial) breast feeding by place of residence and education

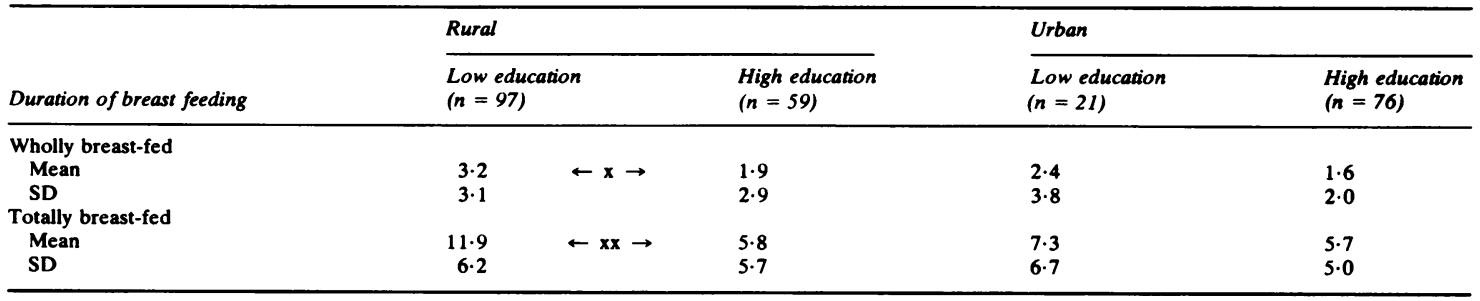

-Difference between means statistically significance $x p<0.01, \quad x x p<0.001$. 
the educated woman. It is important to note that rural women of low education show the longest average duration of breast-feeding-almost one year.

\section{USE OF HEALTH SERVICES}

In investigating the differential use of health services by women in the study sample as a factor affecting the health of their infants we shall consider the place and attendant at delivery of the study infant, the immunisation pattern, and the frequency and purpose of visits to health practitioners for the infant during the first 18 months of life.

\section{Attendant at delivery}

Table 4 presents the distribution of women by the type of attendant at delivery of the infants in the study. About one-third of all rural and urban women in the two education groups were delivered by a trained midwife. Untrained midwives, who do not receive formal education in midwifery, locally called dayeh, delivered more than half of the rural women with low education, while doctors delivered the largest proportion of educated rural women and of women living in urban areas.

\section{Pattern of immunisation}

Data on patterns of polio and DPT immunisation are shown in tables 5 and 6 , respectively. A large proportion of infants in both rural and urban areas, observed until aged about 18 months were not immunised for polio (40\%) and DPT (65\%). Immunisation against measles was extremely low, with $93 \%$ of the infants not immunised.

A difference in immunisation pattern by education and by place of residence was shown for both polio and DPT. In the rural sample there was a significant

Table 4 Distribution of women by attendant at delivery, place of residence, and education

\begin{tabular}{|c|c|c|c|c|c|c|c|c|c|c|}
\hline \multirow{3}{*}{$\begin{array}{l}\text { Attendant at } \\
\text { delivery }\end{array}$} & \multicolumn{4}{|c|}{ Rural } & \multicolumn{4}{|c|}{ Urban } & \multicolumn{2}{|c|}{ Total } \\
\hline & \multicolumn{2}{|l|}{ Low } & \multicolumn{2}{|c|}{ High } & \multicolumn{2}{|c|}{ Low } & \multicolumn{2}{|c|}{ High } & \multirow[b]{2}{*}{ No } & \multirow[b]{2}{*}{$\%$} \\
\hline & No & $\%$ & No & $\%$ & No & $\%$ & No & $\%$ & & \\
\hline $\begin{array}{r}\text { Untrained } \\
\text { midwife } \\
\text { (dayeh) }\end{array}$ & 51 & $52 \cdot 5$ & 9 & $15 \cdot 3$ & 4 & $19 \cdot 1$ & 6 & $7 \cdot 9$ & 70 & 27.7 \\
\hline
\end{tabular}

$\chi_{0}^{2}=65.9 ; \mathrm{p}<0.005$

Table 5 Distribution of women by their infant's age at polio immunisation, place of residence, and education

\begin{tabular}{|c|c|c|c|c|c|c|c|c|c|c|}
\hline \multirow{3}{*}{$\begin{array}{l}\text { Age at polio } \\
\text { immunisation } \\
\text { (months) }\end{array}$} & \multicolumn{4}{|c|}{ Rural } & \multicolumn{4}{|c|}{ Urban } & \multicolumn{2}{|c|}{ Total } \\
\hline & \multicolumn{2}{|l|}{ Low } & \multicolumn{2}{|c|}{ High } & \multicolumn{2}{|c|}{ Low } & \multicolumn{2}{|c|}{ High } & \multirow[b]{2}{*}{$N o$} & \multirow[b]{2}{*}{$\%$} \\
\hline & No & $\%$ & No & $\%$ & No & $\%$ & No & $\%$ & & \\
\hline $0-3$ & 11 & $11 \cdot 3$ & 26 & $44 \cdot 1$ & 7 & $33 \cdot 3$ & 34 & $44 \cdot 7$ & 78 & $30 \cdot 8$ \\
\hline $4-6$ & 31 & 32.0 & 15 & 25.4 & 4 & 19.0 & 16 & $21 \cdot 1$ & 66 & $26 \cdot 1$ \\
\hline$\geqslant 7$ & 2 & $2 \cdot 1$ & 0 & 0.0 & 1 & $4 \cdot 8$ & 4 & $5 \cdot 3$ & 7 & $2 \cdot 8$ \\
\hline Not immunised & 53 & $54 \cdot 6$ & 18 & $30 \cdot 5$ & 9 & 42.9 & 22 & 28.9 & 102 & $40 \cdot 3$ \\
\hline Total & 97 & $100 \cdot 0$ & 59 & $100 \cdot 0$ & 21 & $100 \cdot 0$ & 76 & $100 \cdot 0$ & 253 & $100 \cdot 0$ \\
\hline
\end{tabular}

Two basic comparisons between urbanisation and education groups were tested for significance, using the $\chi^{2}$ test, with data from this table: (1) comparison of proportions non-immunised and (2) for immunised children, comparison of distributions into a collapsed age grouping (0-3, $\geqslant 4$ ). .

Table 6 Distribution of women by their infant's age at DPT immunisation, place of residence, and education

\begin{tabular}{|c|c|c|c|c|c|c|c|c|c|c|}
\hline \multirow{3}{*}{$\begin{array}{l}\text { Age at DPT } \\
\text { immunisation } \\
\text { (months) }\end{array}$} & \multicolumn{4}{|c|}{ Rural } & \multicolumn{4}{|c|}{ Urban } & \multicolumn{2}{|c|}{ Total } \\
\hline & \multicolumn{2}{|c|}{ Low } & \multicolumn{2}{|c|}{ High } & \multicolumn{2}{|c|}{ Low } & \multicolumn{2}{|c|}{ High } & \multirow[b]{2}{*}{ No } & \multirow[b]{2}{*}{$\%$} \\
\hline & No & $\%$ & No & $\%$ & No & $\%$ & No & $\%$ & & \\
\hline $0-3$ & 6 & $6 \cdot 2$ & 6 & $10 \cdot 2$ & 3 & $14 \cdot 3$ & 17 & $22 \cdot 4$ & 32 & $12 \cdot 7$ \\
\hline $4-6$ & 10 & $10 \cdot 3$ & 15 & 25.4 & 4 & $19 \cdot 0$ & 13 & $17 \cdot 1$ & 42 & $16 \cdot 6$ \\
\hline$\geqslant 7$ & 1 & $1 \cdot 0$ & 3 & $5 \cdot 1$ & 0 & 0.0 & 10 & $13 \cdot 2$ & 14 & $5 \cdot 5$ \\
\hline Total & 97 & $100 \cdot 0$ & 59 & $100 \cdot 0$ & 21 & $100 \cdot 0$ & 76 & $100 \cdot 0$ & 253 & $100 \cdot 0$ \\
\hline
\end{tabular}

Footnote, see table 5 . 
difference in the proportion of infants not immunised against polio whose mothers had low education as compared with infants of educated women $(p<0.001)$. In the urban sample, on the other hand, although infants of educated women showed a higher proportion immunised against polio, the difference between the education groups was not significant. Controlling for education, no significant difference in the proportion immunised against polio was observed between the urban and rural samples. For DPT, significant differences were observed within rural and urban women between education groups $(p<0.001$ and $p<0.05$, respectively). In summary, for both polio and DPT immunisation, the infants who were least immunised were those of rural mothers with low education.

As for the age at which the infants were immunised against polio, for more than half of those immunised in all groups immunisation was started within the recommended three months after birth, except for the infants of rural women with low education of which only a quarter received immunisation in that period. Within the rural sample, for infants of women with low education immunisation was started at a significantly later age than infants of educated women $(p<0.005)$. No such difference in age at immunisation was shown within the urban sample by education level. Controlling for education, rural women with low education started immunisation of their infants at a significantly later age than their urban counterparts $(p<0.05)$, whereas there was no significant difference for educated women.

The pattern of DPT immunisation with respect to age at which immunisation was received is similar to that described for polio, with the infants of rural women of low education showing the latest age at immunisation. No significant difference, however, was observed between the various groups of the study.

\section{Visits to health practitioners}

The women in the study sample were asked at each interview whether or not they had taken their infants to a health practitioner and the purpose of such visits. This is taken as a measure of the use of health services and as an indication of the morbidity pattern in the first 18 months of life. Out of a total of 1131 such visits (an average of 4.5 visits per woman), only one visit was to a nurse and the rest were all to doctors. The most important purpose reported was intestinal complaints, showing highest prevalence in the summer months, and respiratory problems occurring mostly in the winter months. The few visits made for well-baby care came very close after birth. Other reasons given for visiting doctors were skin problems and after the first six months, dental problems.
Measles was a conspicuous problem in both rural and urban areas in the spring and early summer months.

The average number of well-baby visits were significantly higher for educated women in both urban and rural areas. The average number of visits for intestinal problems, on the other hand, showed a negative relation by educational level, with educated women showing a significantly lower average number of visits for both areas. For respiratory illnesses, there was no significant difference in average frequency of visits by education, but significantly higher average frequency was observed for urban areas than for rural areas for both education groups.

\section{Discussion}

The findings in this study describe patterns of family formation, infant feeding, and use of health care, by education and place of residence among newly delivered mothers residing in the southern district of Lebanon. These behaviour patterns are important because of their implication for the health and growth of the newborn infant.

Family environment-The findings showed a rapid rate of reproduction, particularly for rural women of low education. Moreover, $40 \%$ of the women in the sample became pregnant again within 18 months of the birth of the study infant. This pattern of early pregnancy leads to premature weaning and interferes with the ability of the mother to provide proper care for the newborn infant in the sensitive first year of life. Early pregnancy in the study sample is largely undesired and a result not of a low incidence of contraception but of the pattern of use. ${ }^{7}$ Some women in the sample still relied on traditional methods of contraception and those taking the pill took periods of rest for fear of the negative effect of the pill on their health.

Breast-feeding patterns-The results showed a negative trend by education-even though the high education group did not represent a level beyond secondary education-and by place of residence of the mother. The decline in breast-feeding with education and urban residence may partly result from increased availability of modern contraceptives, which reduce the reliance on the contraceptive effect of breast-feeding. ${ }^{78}$ Family planning programmes, therefore, have a responsibility to support breast-feeding as a method of infant feeding and to encourage a pattern of contraceptive use postpartum consistent with the woman's desire to breast-feed. ${ }^{7} 9$

Use of health services-Women with both education and urban residence tended to be delivered by doctors. Most $(52 \cdot 2 \%)$ rural women with low education continued to be attended by untrained midwives, the dayehs. Such traditional 
practitioners accumulate their knowledge through apprenticeship and experience, and usually do well for normal deliveries. Nevertheless, they may not be able to deal adequately with major problems arising during delivery. By training local dayehs, the supply of trained midwives can be increased. A referral network should link midwives to doctors, however, for handling difficult deliveries.

Immunisation-Substantial proportions of children in both rural and urban areas had not been immunised for polio and DPT at 18 months. Moreover, most mothers who started immunisation for their infants did so after the recommended age of 2 to 3 months. Rural infants of mothers with low education had the worst pattern of immunisation, indicating that education and city dwelling probably provided more awareness, acceptance, and availability of immunisation services.

Well-baby services-These were used significantly more by women living in urban areas and by educated women. The level of use, however, even for these women remained far below that desired.

Morbidity patterns-It must be indicated, firstly, that the measure used-namely, illnesses resulting in a visit to a health practitioner-probably reflects the more severe episodes. Intestinal diseases have a high frequency in summer, as observed in other developing countries. Diarrheal problems, which result from poor sanitary conditions, may have a damaging effect on the survival and growth of infants. ${ }^{10}$ These illnesses respond dramatically to rehydration by mouth and to improvements in sanitary conditions. ${ }^{11}$ In winter months respiratory illnesses were common, more so in the urban areas. This is probably partly a result of a higher level of exposure because of the crowded housing conditions.

\section{Conclusion}

This study has shown that educated women and women living in urban areas, as compared with rural women of low education, have better practices in family formation patterns, immunisation, and well-baby care. The importance of educating women, particularly in rural areas, as a policy variable to improving levels of child health and growth, is thus emphasised. Educated women, however, did not achieve the desired level of well-baby care, and education had a negative effect on patterns of breast-feeding. This study thus underscores the special need for health education programmes to emphasise to all mothers proper breast-feeding and contraceptive practices postpartum, and the importance of preventive health care for infants.
Dayehs and trained midwives still play a substantial part as attendants at delivery. All women, however, demanded the services of doctors for the care of their infants. Demand is certainly affected by the available supply. There is, thus, a definite need to introduce into the system properly trained paramedical staff who can make simple services more available, particularly in rural areas, and who can free doctors to handle more specialised and difficult cases. A specially important element in the delivery of primary health care is the public health nurse who can establish contacts with mothers through regular visits for health education, immunisation, prenatal and postnatal care, family planning advice, and follow-up services.

This study was supported by a grant from the Ford Foundation under the Ford and Rockefeller Foundations' Research Program on Population and Development policy. We acknowledge the co-operation of the Lebanon Family Planning Association and the participation of Ms Hiam Shedid, Ms Hiam Fakih, Ms Samia Ibrahim, and Ms Suzy Kabakian during the various stages of the study.

\section{References}

${ }^{1}$ Harfouche JK. Health care problems of the young child in a developing ecological context. Bull WHO 1979; 57: 387-403.

${ }^{2}$ Morley D. Paediatric priorities in the developing world. London: Butterworth, 1973.

${ }^{3}$ Ebrahim GL. Delivery of health care to children in the developing countries. Clin Pediatr 1974; 13: 777-82.

${ }^{4}$ Azar J, Churchill C, Loehing I, Zurayk H. In: Omran A, Standley C, eds. Family formation patterns and health. Geneva: World Health Organisation, 1976.

${ }^{5} \mathrm{Jellife}$ DB, Jellife EFP. Human milk in the modern world. Oxford: Oxford University Press, 1978.

${ }^{6}$ Harfouche JK. The importance of breast-feeding. J Trop Pediatr 1970; 16: 135-75.

${ }^{7}$ Zurayk HC. Breast-feeding and contraceptive patterns Post-partum: a study in south Lebanon. Studies in Family Planning 1981; 12: 237-47.

${ }^{8}$ Zurayk HC, Shedid H. The trend away from breast-feeding in a developing country: a women's perspective. J Trop Pediatr (in press).

${ }^{9}$ Simpson-Herbert M, Huffman SL. The contraceptive effect of breast-feeding. Studies in Family Planning 1981; 12: 125-33.

${ }^{10} \mathrm{Ciba}$ Foundation. Acute diarrhea in childhood. Amsterdam: Elsevier Scientific Publishing Company, 1976.

${ }^{11}$ World Health Organisation. Clinical management of acute diarrhea. Geneva: WHO, 1978. 